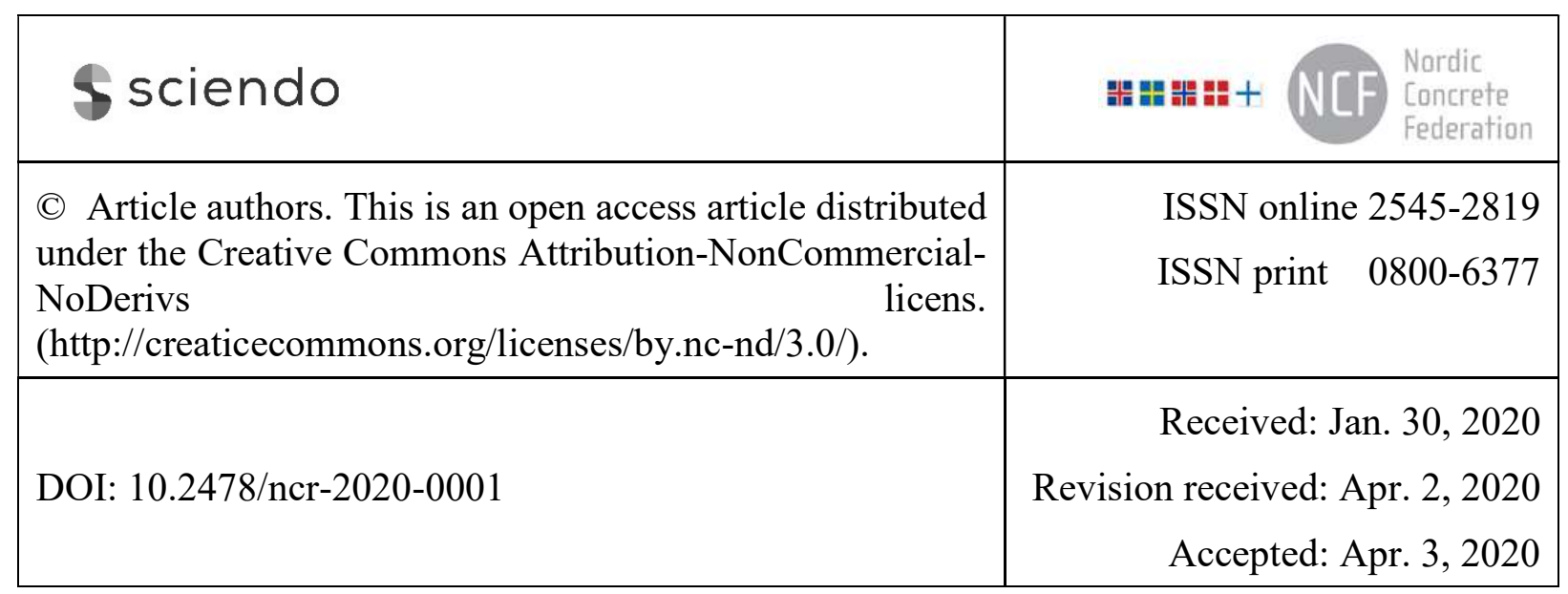

\title{
Bauxite Residue as Supplementary Cementitious Material - Efforts to Reduce the Amount of Soluble Sodium
}

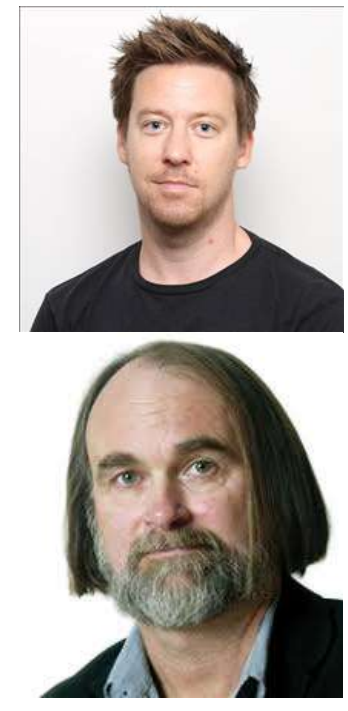

Tobias Danner, PhD

Scientist, SINTEF Community

Høgskoleringen 7B, 7034 Trondheim

Tobias.danner@sintef.no

Harald Justnes, PhD

Chief scientist, SINTEF Community

Høgskoleringen 7B, 7034 Trondheim

Harald.justnes@sintef.no

\begin{abstract}
This study investigates the feasibility of using bauxite residue (BR) as supplementary cementitious material (SCM) for the cement and concrete industry. It is shown from pastes of BR and calcium hydroxide, that BR is highly pozzolanic in nature. The early hydration of cement pastes with BR is accelerated while long-term strength is reduced probably due to the alkaline nature of BR. To be used as cement replacement material in concrete, attempts have been made to reduce the alkali content of $\mathrm{BR}$, in particular to reduce the chance of alkali-aggregate reactions. Co-calcination of BR with kaolin or washing and cooking of BR with calcium hydroxide or calcium hydroxide and gypsum resulted in considerable reduction of alkali content; up to $75 \%$. At the same time the reactivity of the BR was reduced but still being higher compared to fly ash already used in the cement industry.
\end{abstract}

Key words: Bauxite residue, pozzolan, cement replacement, hydration, alkalis, calcination. 
1.

\section{INTRODUCTION}

Bauxite residue (BR; also called "red mud") is a waste product from the Bayer process in making alumina $\left(\mathrm{Al}_{2} \mathrm{O}_{3}\right)$ as raw material for aluminium metal production. BR is the insoluble product after bauxite digestion with sodium hydroxide. Bauxite residue has a complex chemical composition and consists of several crystalline phases, mainly iron oxides and hydroxides but also including aluminium hydroxides, sodalites, quartz, rutile and many others besides some organic materials [1]. BR exits the Bayer process as a highly alkaline slurry of $\mathrm{pH} 10-13.5$ with a solid content between $15-40 \%$ [2] and is pumped away for disposal. The disposal is often just in form of a suspension in big reservoirs and can be a threat to the environment due to its toxic high alkaline nature. BR slurry can also be filter-pressed to a solids content $>75 \%$ before land-filling [3]. Per ton alumina produced between 0.8-1.5 tons of BR are produced [4] resulting in an estimated worldwide reserve larger than 2.7 billion tonnes [5].

There is a lot of research going on to utilize and recycle bauxite residue [5] including potential applications in the construction industry [6]. However, many processes seem not economically feasible yet to reuse the large amounts of available disposed BR. The cement industry might be the only industry with sufficiently high volumes produced globally to tackle the high amount of bauxite residue produced every year and it is therefore necessary to also investigate the feasibility of BR to be used as a supplementary cementitious material (SCM).

The cement industry itself is working constantly on strategies to reduce the $\mathrm{CO}_{2}$ emissions accompanied with its production [7]. Some sources estimate the share of cement production in total anthropogenic $\mathrm{CO}_{2}$ emissions to be around $10 \%$ [8]. In Norway, fly ash is the most used supplementary cementitious material to replace parts of the cement in blended cements. As the amount of coal firing power plants is decreasing in Europe the supply of good quality fly ash will also decrease in the future. Consequently, it is necessary to look for alternative materials to be used as cement replacement to continue the sustainable development of the cement industry.

Ribeiro et al [8] showed that untreated red mud does have pozzolanic properties according to the Brazilian standard NBR 5751 and NBR 5752. The 28-day strength of mortars decreased with increasing replacement levels from 5-50\%. Still, it was concluded that mortars with 50\% replacement of cement by BR show suitable strength for non-structural applications [8]. Most studies in literature confirm long term strength reduction of mortar or concrete to different degrees compared to a reference when replacement levels of cement are higher than 5\% [9]. The strength does not drop over time, it seems just to flatten out while strength of mortar with $100 \%$ cement continues to grow. On the other hand, addition of bauxite residue can increase the durability of concrete by means of chloride and carbonation resistance due to pore refinement $[10,11]$. It is even reported that BR can act as a corrosion inhibitor by forming a passivating layer around steel reinforcement in reinforced concrete [12].

However, bauxite residue contains usually between $2-10 \% \mathrm{Na}_{2} \mathrm{O}$ [3], which most probably will have a negative impact with respect to alkali-aggregate reactions in concrete. Therefore, BR can 
only be accepted as a cement replacement material in concrete if the alkali content can be reduced. Decreasing the sodium content of BR is also a consideration for waste management and several approaches are being tested in the laboratory, e.g. treatment with Fe- or Al-sulphates [13]. Other efforts to reduce the $\mathrm{pH}$ and the soluble $\mathrm{Na}$ content of $\mathrm{BR}$ include acid neutralization, seawater neutralization, $\mathrm{CO}_{2}$ treatment, bioleaching and sintering [3]. A recent review article gives an overview of alkalinity reduction of BR by utilizing other industrial wastes such as waste acid, brines or biomass [14]. The study performed and described here, investigates the feasibility of BR as a pozzolanic material and reports first attempts to reduce the alkali content while keeping the reactivity sufficiently high to be used as SCM in the cement industry.

\section{MATERIALS}

The chemical compositions of Portland cement (PC) and bauxite residue (BR) are given in Table 1. As PC, a CEM I containing 4.9\% limestone was used as delivered from Norcem, Brevik, Norway. The bauxite residue filter cake was received from a plant in Brazil. The received BR sample contained $22 \%$ moisture measured by weight loss after gentle drying at $50^{\circ} \mathrm{C}$ for 3 days and confirmed by drying over night at $105^{\circ} \mathrm{C}$. The $\mathrm{BR}$ dried at $50^{\circ} \mathrm{C}$ was milled down gently to break down bigger lumps but without using grinding force. The measured particle size distribution showed $\mathrm{d}_{50}$ values of around $5 \mu \mathrm{m}$, i.e. $50 \%$ of the volume had a particle size $<5 \mu \mathrm{m}$. The BET surface area of BR dried at $50^{\circ} \mathrm{C}$ was $9.4 \mathrm{~m}^{2} / \mathrm{g}$.

Table 2 shows the mineralogical composition of BR determined by Rietveld analysis [15]. The results show that BR contains about $40 \%$ amorph material. XRD and TG/DTG results of dried red mud are shown in Figure 1. The weight losses at around $300^{\circ} \mathrm{C}$ in the TG/DTG curve correspond with the dehydroxylation of Fe- and Al-hydroxides (goethite and gibbsite).

Reagent grade calcium hydroxide $(\mathrm{CH})$ calcium carbonate $(\mathrm{CC})$ and kaolinite $(\mathrm{K})$ was used in the different tests performed as described in the next section.

Table 1 - Chemical composition (in \%) of PC and BR determined with X-ray fluorescence (XRF)

\begin{tabular}{lll}
\hline Oxides & CEM I & BR \\
\hline $\mathrm{Fe}_{2} \mathrm{O}_{3}$ & 3.1 & 35.3 \\
$\mathrm{TiO}_{2}$ & - & 4.9 \\
$\mathrm{CaO}$ & 61.5 & 1.6 \\
$\mathrm{~K}_{2} \mathrm{O}$ & 1.1 & 0.3 \\
$\mathrm{SiO}_{2}$ & 19.5 & 15.6 \\
$\mathrm{Al}_{2} \mathrm{O}_{3}$ & 4.7 & 20.9 \\
$\mathrm{MgO}$ & 2.3 & 0.1 \\
$\mathrm{Na}_{2} \mathrm{O}$ & 0.4 & 9.2 \\
$\mathrm{SO}$ & 3.9 & - \\
$\mathrm{LOI}$ & 2.7 & 9.0 \\
\hline $\mathrm{SUM}$ & 99.2 & 96.9 \\
\hline
\end{tabular}


Table 2 - Mineralogical composition of bauxite residue determined by X-ray diffraction (XRD) and Rietveld analysis

\begin{tabular}{lll}
\hline Mineral name & Chemical formula & Rietveld weight \% \\
\hline Quartz & $\mathrm{SiO}_{2}$ & 2.1 \\
Ilmenite & $\mathrm{FeTiO}_{3}$ & 1.5 \\
Hematite & $\mathrm{Fe}_{2} \mathrm{O}_{3}$ & 22.7 \\
Anatase & $\mathrm{TiO}_{2}$ & 3.6 \\
Rutile & $\mathrm{TiO}_{2}$ & 0.7 \\
Zircon & $\mathrm{ZrO}_{2}$ & 0.2 \\
Goethite & $\mathrm{FeOOH}_{\text {Gibsite }}$ & 12.1 \\
Sodalite & $\mathrm{Al}_{(}(\mathrm{OH})_{3}$ & 6.2 \\
\hline SUM crystalline & & 7.9 \\
\hline SUM amorphous & & 57.1 \\
\hline
\end{tabular}
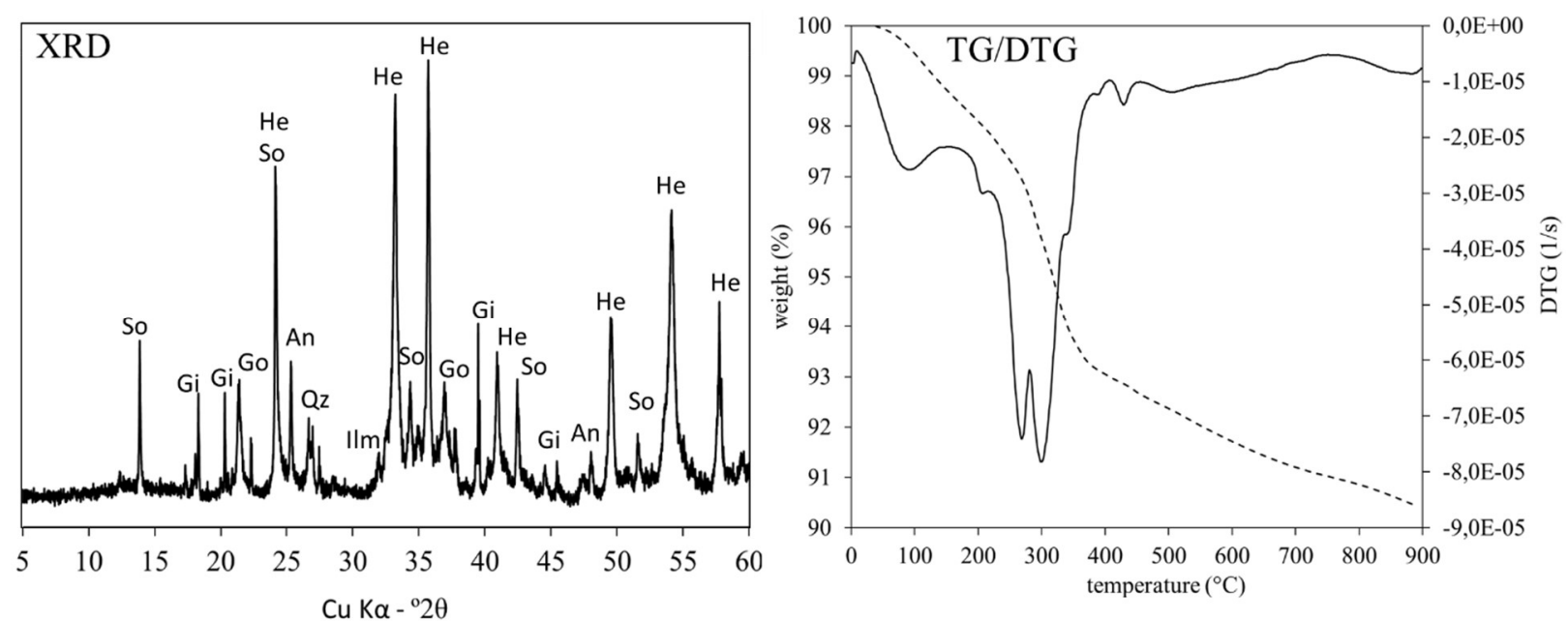

Figure $1-X R D$ and TG/DTG of dried red mud (So = sodalite, He = hematite, $Q z=$ quartz, $G o=$ goethite and $G i=$ gibbsite, An = anatase, Ilm = ilmenite)

\section{METHODS}

The chemical composition of PC and BR was analysed with $X$-Ray Fluorescence $(X R F)$ with a Bruker AXS S8 Tiger WDXRF with a $4 \mathrm{~kW}$ generator, using molten glass disks.

Qualitative $X$-ray diffraction (XRD) was performed on a Bruker D8 Focus instrument equipped with a Lynx Eye detector and a standard copper $(\mathrm{Cu}-\mathrm{K} \alpha) \mathrm{X}$-Ray source. A $0.2 \mathrm{~mm}$ divergence slit was used, and measurements were taken from $5-60^{\circ} 2 \theta$ with a step size of $0.2^{\circ} 2 \theta$ and $0.8 \mathrm{~s}$ time per step. Quantitative mineralogical analysis was performed by Rietveld analysis using the Topas Software version 4.2 and the ICDD PDF4+ mineral structure database. Quantification of amorphous phases was done by the external standard method also called "G-factor method" in some places [15-17], by using an external quartzite standard. The quartzite was calibrated against a silicon powder from NIST (Standard Reference Material 640d) [15].

Thermogravimetric analysis (TGA) was performed with a Mettler Toledo TGA/SDTA 851. Samples were analysed with a heating rate of $10^{\circ} \mathrm{C} / \mathrm{min}$ between $40-900^{\circ} \mathrm{C}$. All measurements 
were performed in nitrogen atmosphere with a flow rate of $50 \mathrm{ml} / \mathrm{min}$. The $\mathrm{CH}$ consumption and bound water in pastes were calculated from the weight loss in the ranges $\sim 400-550^{\circ} \mathrm{C}$ and 0 $350^{\circ} \mathrm{C}$, respectively. The exact boundaries for $\mathrm{CH}$ consumption were chosen from the peak in the DTG curve.

Pozzolanic activity was tested according to lime consumption test where SCM samples were mixed with $\mathrm{CH}$ in a ratio of $2: 1$ and a water to binder ratio of 1 . Artificial pore water $(\mathrm{pH}=13.2$; $\mathrm{KOH} / \mathrm{NaOH}=2 / 1$ ) was used as mixing water and pastes were mixed for 1 min by hand with a plastic spatula. The mixed pastes were stored sealed in glass ampules in a temperature-controlled room for curing. The hydration of the pastes was stopped by crushing the samples to fine powder and subsequent solvent exchange. After filtration, the samples were dried at about $35 \%$ relative humidity $(\mathrm{RH})$ in a closed desiccator containing $\mathrm{CaCl}_{2}$ saturated water.

$R^{3}$-test stands for a rapid, relevant and reliable procedure to test the chemical reactivity of materials (SCMs) in a simplified cementitious system. The $\mathrm{R}^{3}$ test was initially developed to predict the reactivity of calcined clays and showed good correlation to 28-day mortar strength where $20-50 \%$ of PC is replaced with the respective material [18]. The test has been used frequently in other projects and proved to also work well for other types of SCMs. The $\mathrm{R}^{3}$ test was performed according to the procedure described for the LC3-50 system from Avet et al. (2016) [18]. The composition of the $\mathrm{R}^{3}$ pastes was about $20 \% \mathrm{SCM}, 65 \% \mathrm{CH}, 10 \% \mathrm{CaCO}_{3}(\mathrm{CC})$, $1 \% \mathrm{~K}_{2} \mathrm{SO}_{4}$ and $0.25 \% \mathrm{KOH}$. The water to binder ratio $(\mathrm{w} / \mathrm{b})$ was 1.2 . The dry materials were weighed into a plastic ampoule and water was added. The pastes were mixed with a Vortex SA6 model at 4500 rounds per minute (rpm) for $1 \mathrm{~min}$ and cured for 2 days at $40^{\circ} \mathrm{C}$. Hydration of pastes was stopped after 2 days by solvent exchange using iso-propanol and diethylether.

Isothermal calorimetry of cement pastes was performed with a TAM Air instrument set to $20^{\circ} \mathrm{C}$. Mixing of the pastes was performed outside the calorimeter. Materials were weighed in directly into plastic ampoules. After injecting the water, the pastes were mixed with a Vortex SA6 mixer for $1 \mathrm{~min}$ at $4500 \mathrm{rpm}$. The water to binder ratio (w/b) was 0.6 . Due to external mixing, the signal from the first $45 \mathrm{~min}$ after mixing was excluded for calculation of the cumulative heat.

Compressive strength of mortars was tested with different substitution levels of PC by BR or Norcem limestone filler. The water to binder ratio $(\mathrm{w} / \mathrm{b})$ was held constant at 0.5 . The moisture content of BR was considered for calculating the correct $\mathrm{w} / \mathrm{b}$. The mortar mixes were cast in three $40 \times 40 \times 160 \mathrm{~mm}$ molds and stored in a cabinet for 24 hours at $23 \pm 2{ }^{\circ} \mathrm{C}$ and $90 \% \mathrm{RH}$. After 24 hours, the mortar prisms were removed from the molds and stored in saturated $\mathrm{CH}$ water for 28 days to avoid leaching.

With the aim of reducing the release of alkali (especially $\mathrm{Na}$ ) from $\mathrm{BR}$ in blends with cement, "co-calcination" and "cooking" experiments were performed.

Co-calcination of BR and kaolinite was performed with the aim of binding $\mathrm{Na}$ in less soluble phases. $70 \%$ BR and 30\% kaolin were homogenised with an auto mortar for 5 min at medium 
pressure to obtain a homogeneous blend. Followed by that batches of about $100 \mathrm{~g}$ material were transformed to platina crucibles and calcined in a chamber furnace at temperatures between 800 and $1100^{\circ} \mathrm{C}$. An overview of the investigated blends is given in Table 3. Samples were inserted directly at high temperature. The residence time in the furnace was between 15 - $45 \mathrm{~min}$. Samples were taken out directly at high temperature and cooled down rapidly by spreading the material out on a metal plate holding $20^{\circ} \mathrm{C}$.

\begin{tabular}{llll}
\multicolumn{5}{c}{ Table 3 - Investigated blends of the co-calcination experiments } \\
\hline No. & $\begin{array}{l}\text { Blend BR and kaolinite }(\mathrm{K}) \\
(\%)\end{array}$ & $\begin{array}{l}\text { Calcination temperature } \\
\left({ }^{\circ} \mathrm{C}\right)\end{array}$ & $\begin{array}{l}\text { Residence time } \\
(\mathrm{min})\end{array}$ \\
\hline 1 & $100 \mathrm{BR}$ & - & - \\
2 & $70 \mathrm{BR} / 30 \mathrm{~K}$ & - & - \\
3 & $70 \mathrm{BR} / 30 \mathrm{~K}$ & 800 & 15 \\
4 & $70 \mathrm{BR} / 30 \mathrm{~K}$ & 1000 & 15 \\
5 & $70 \mathrm{BR} / 30 \mathrm{~K}$ & 1100 & 15 \\
6 & $70 \mathrm{BR} / 30 \mathrm{~K}$ & 1100 & 45 \\
\hline
\end{tabular}

Cooking of BR with portlandite $(\mathrm{CH})$ or $\mathrm{CH}$ and gypsum $\left(\mathrm{CS}_{\mathrm{S}} \mathrm{H}_{2}\right)$ was performed on a laboratory heating plate. First, BR was washed with water two times and filtrated to remove easily soluble alkalis. Followed by that, blends of (a) $60 \% \mathrm{BR}$ and $40 \% \mathrm{CH}$ and (b) $60 \% \mathrm{BR}, 20 \% \mathrm{CH}$ and $20 \%$ $\mathrm{CSSH}_{2}$ were prepared. The blends were mixed in a metal bowl with excess water $(\mathrm{w} / \mathrm{b}=5.7)$ and put on a heating plate. The mix was heated up for about 15 min until cooking and subsequently cooked for $45 \mathrm{~min}$. During the whole cooking process a magnetic stirrer was used for constant stirring. After cooking, a sample of the solution was taken, centrifuged and filtrated through filter paper. The cooked mixture was washed two times with excess water and filtrated. The wet mixture was transferred into another metal bowl and put in a furnace for drying over night at $105^{\circ} \mathrm{C}$.

Alkali release of materials was tested by ion exchange with calcium from $\mathrm{CH}$. $30 \mathrm{ml}$ distilled water was added to about $5 \mathrm{~g}$ sample to be tested and $5 \mathrm{~g} \mathrm{CH}$ in a plastic tube sealed with a screw cap. The tube was shaken vigorously at first and then left standing for $24 \mathrm{~h}$ while shaking occasionally. The tubes were then centrifuged at $4000 \mathrm{rpm}$ for 5 minutes and the surface water was decanted off the sample. The water was then filtrated before being analysed with respect to sodium $(\mathrm{Na})$ content by a Sherwood Flame Photometer, model 410. This is considered a quick test for alkali binding.

Alkali release was furthermore tested in cement pastes. Cement pastes were made out of $100 \mathrm{~g}$ cement, $25 \mathrm{~g}$ sample to be tested $(20 \%$ of total powder) and $87.5 \mathrm{~g}$ water $(\mathrm{w} / \mathrm{b}=0.70)$. The total volume of the paste was about $130 \mathrm{ml}$, which was mixed in a high shear blender. The paste was filled in $125 \mathrm{ml} \mathrm{pp-bottles} \mathrm{with} \mathrm{screw} \mathrm{cap} \mathrm{and} \mathrm{cured} \mathrm{for} 40$ days at $20^{\circ} \mathrm{C}$. Then the pore fluid was pressed from the samples with a special tool and analysed for sodium (Na) and potassium $(\mathrm{K})$ with the Sherwood Flame Photometer, model 410. This test is slower, but more realistic compared to the lime test, and it also accounts for the additional alkali binding in gels like NASH and CNASH in cementitious systems where also silicate is involved. 


\subsection{Bauxite residue as SCM}

The pozzolanic reactivity of $\mathrm{BR}$ was investigated in pastes of $\mathrm{BR}$ and $\mathrm{CH}$ mixed with an alkaline solution. Figure 2 shows the results of the pastes directly after mixing ( 0 days) and after hydration for 28 days. The amount of $\mathrm{CH}$ in the pastes was calculated from the weight loss in the TG curve between 390 and $550^{\circ} \mathrm{C}$ corresponding to the dehydroxylation temperature range of $\mathrm{CH}$. The amount of bound water was calculated by the weight loss between 40 and $390^{\circ} \mathrm{C}$ and normalized to dry weight at $390^{\circ} \mathrm{C}$, thus excluding weight losses from $\mathrm{CH}$ and $\mathrm{CC}$. Regarding the mineralogical composition, goethite and gibbsite will at least in the initial dry mixes and probably right after mixing with water contribute to a weight loss due to dehydroxylation at around $300^{\circ} \mathrm{C}$. With respect to the chemical composition and the amount of structural water, the dehydroxylation of goethite and gibbsite can account for about $2.2 \%$ of calculated bound water in the initial dry mix. Results of amounts of $\mathrm{CH}$ and bound water are given in Table 4 . The values given for the initial dry mix are based on theoretical calculations and not measured with TG/DTG. At 0 days right after mixing the paste (about $10 \mathrm{~min}$ ), a small amount of $\mathrm{CH}$ has reacted already, and the amount of bound water increased right away. The amorphous part of sodalite in BR may have a fast initial pozzolanic reaction at its surface with water to form AFm phases as shown by the weight loss around $160^{\circ} \mathrm{C}$ in Figure 2, typical for calcium aluminate hydrates. Assuming the signals around $300^{\circ} \mathrm{C}$ are due to dehydroxylation of goethite and gibbsite, the amount of bound water in AFm is still almost 5\%. After 28 days of hydration substantial amounts of $\mathrm{CH}$ are consumed in the pozzolanic reaction and only about $5 \% \mathrm{CH}$ are left in the paste. The amount of bound water increased from 7 to $17 \%$ between 0 and 28 days. Both peaks at around $160-180^{\circ} \mathrm{C}$ and around $300^{\circ} \mathrm{C}$ increased considerably. The peak at $300^{\circ} \mathrm{C}$ might be associated with dehydroxylation of a hydrogrossular phase like katoite $\left(\mathrm{Ca}_{3} \mathrm{Al}_{2}\left(\mathrm{SiO}_{4}\right)_{3-x}(\mathrm{OH})_{4 x}, 1.5<x<3\right)$. The presence of katoite was confirmed with XRD. Formation of AFm phases was confirmed by detection of hemicarboaluminate hydrate and strätlingite. Due to reaction with Fe-rich BR, Fe substituted hemicarboaluminate hydrate [19] was found additionally.
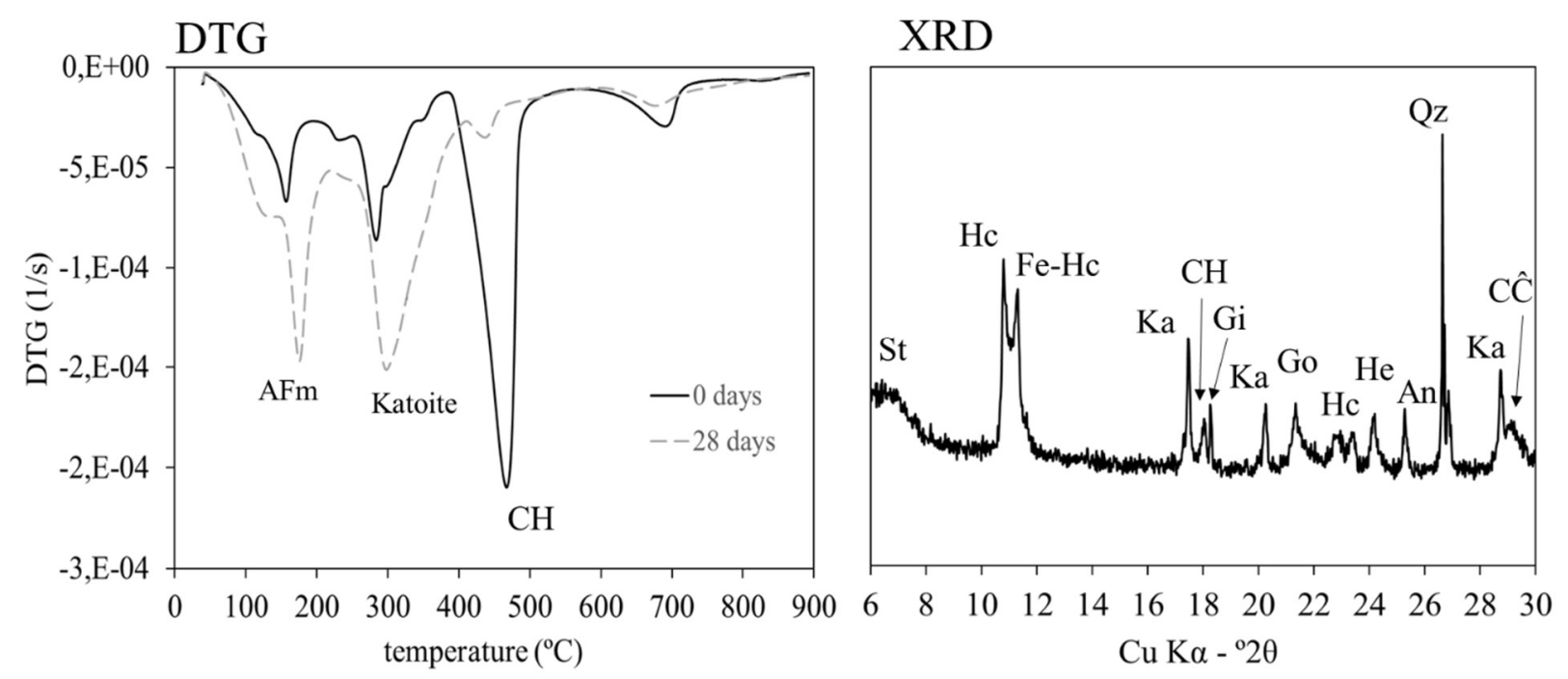

Figure 2 - Left: DTG curves of BR/CH pastes hydrated for 0 and 28 days. Right: XRD of the $\mathrm{BR} / \mathrm{CH}$ paste after hydration for 28 days ( $\mathrm{Hc}=$ hemicarboaluminate hydrate, $\mathrm{Fe}-\mathrm{Hc}=\mathrm{Fe}$ substituted hemicarboaluminate hydrate, $S t=$ strätlingite, $\mathrm{Ka}=$ katoite, $\mathrm{CH}=$ portlandite, $\mathrm{Go}=$ goethite, $\mathrm{He}=$ hematite, $\mathrm{An}=$ anatase, $\mathrm{C} \hat{C}=$ calcite) 
Nordic Concrete Research - Publ. No. NCR 62 - ISSUE 1 / 2020 - Article 1, pp. 1-20

Table 4 - Amount of $\mathrm{CH}$ and bound water in dry and hydrated BR/CH pastes

\begin{tabular}{cccc}
\hline & $\begin{array}{c}\text { Initial dry mix } \\
\text { (theoretical) }\end{array}$ & $\begin{array}{c}\text { 0 days } \\
\text { (measured) }\end{array}$ & $\begin{array}{c}28 \text { days } \\
\text { (measured) }\end{array}$ \\
\hline $\mathrm{CH}\left(\%\right.$ by dry weight at $\left.390^{\circ} \mathrm{C}\right)$ & 33.3 & 30.1 & 4.9 \\
Bound water $\left(\%\right.$ by dry weight at $\left.390^{\circ} \mathrm{C}\right)$ & $\sim 2.2$ & 7.4 & 17.2 \\
\hline
\end{tabular}

DTG and XRD of the hydrated paste from the $\mathrm{R}^{3}$ Test is shown in Figure 3 . The amount of bound water in the $\mathrm{R}^{3}$ paste was $10.5 \%$. This is comparable with the reactivity of silica fume [20] in the same test. On the other hand, values for siliceous fly ash were around 4\% [20] with the same test procedure. This confirms that the BR is very reactive in nature. In the $\mathrm{R}^{3}$ test, the main hydration product was monocarboaluminate type AFm due to the reaction between aluminate rich species of the BR with $\mathrm{CH}$ and $\mathrm{C} \hat{\mathrm{C}}$. No katoite was found in the $\mathrm{R}^{3}$ pastes, probably due to the high amount of $\mathrm{C} \hat{C}$ present, converting all katoite to calcium monocarboaluminate hydrate.
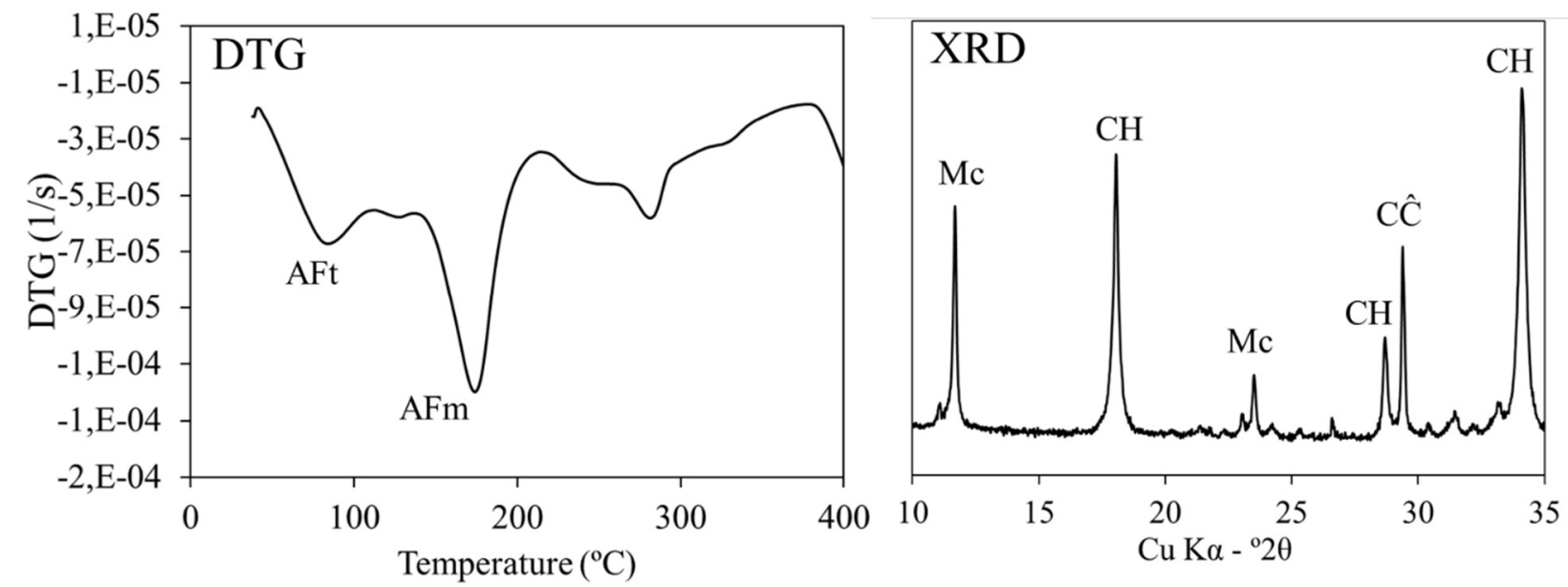

Figure 3 - DTG (left) and XRD (right) of hydrated $R^{3}$ test paste $(M c=$ calcium monocarboaluminate hydrate, $C \hat{C}=$ calcite, $C H=$ portlandite, calcium hydroxide)

To study the effect of the BR addition on cement hydration, $20 \%$ of cement was replaced by BR and pastes were investigated with isothermal calorimetry. Additional mixes were prepared with $20 \%$ BR and 5\% limestone (LL), and 20\% limestone. Addition of 5\% limestone to BR will favour the formation of calcium monocarboaluminate hydrate as in the well-known synergy effect of cement with reactive alumina and limestone first identified by De Weerdt et al. [21-23] for fly ash and later by Danner $[24,25]$ for clay and utilized by Scrivener in the LC $^{3}$ concept [26]. The formation of calcium monocarboaluminate hydrate on expense of katoite results in a higher amount of bound water which can lead to increased strength and lower permeability of the hydrated pastes.

The heat of hydration curve and the cumulative heat development of cement pastes with and without BR and/or limestone filler (LL) are given in Figure 4. The curve of the reference sample (REF PC) shows the typical behaviour of cement hydration with two main peaks in the acceleration period for the hydration reactions of calcium silicates and calcium aluminates (sulphate depletion) [27]. Even though the REF PC is a rapid cement, it seems that the cement hydration is considerably accelerated by BR in terms of setting time (major peak starting earlier) 
and acceleration (first slope of major peak slightly steeper). For comparison, adding limestone filler does not change the setting behaviour but decreases the hydration rate (lower maximum heat flow), due to dilution of the cement. The accelerated setting can also be seen in the cumulative heat curve of the pastes. Accelerated setting time of mortars prepared with different additions of BR was also observed by others and explained due to the presence of aluminium and sodium hydroxides which are known setting accelerators [28]. The cumulative heat after 2-3 days of hydration was decreased when replacing PC by BR and limestone. XRD analysis of the pastes hardened for 28 days confirmed that no katoite was formed in cement pastes.
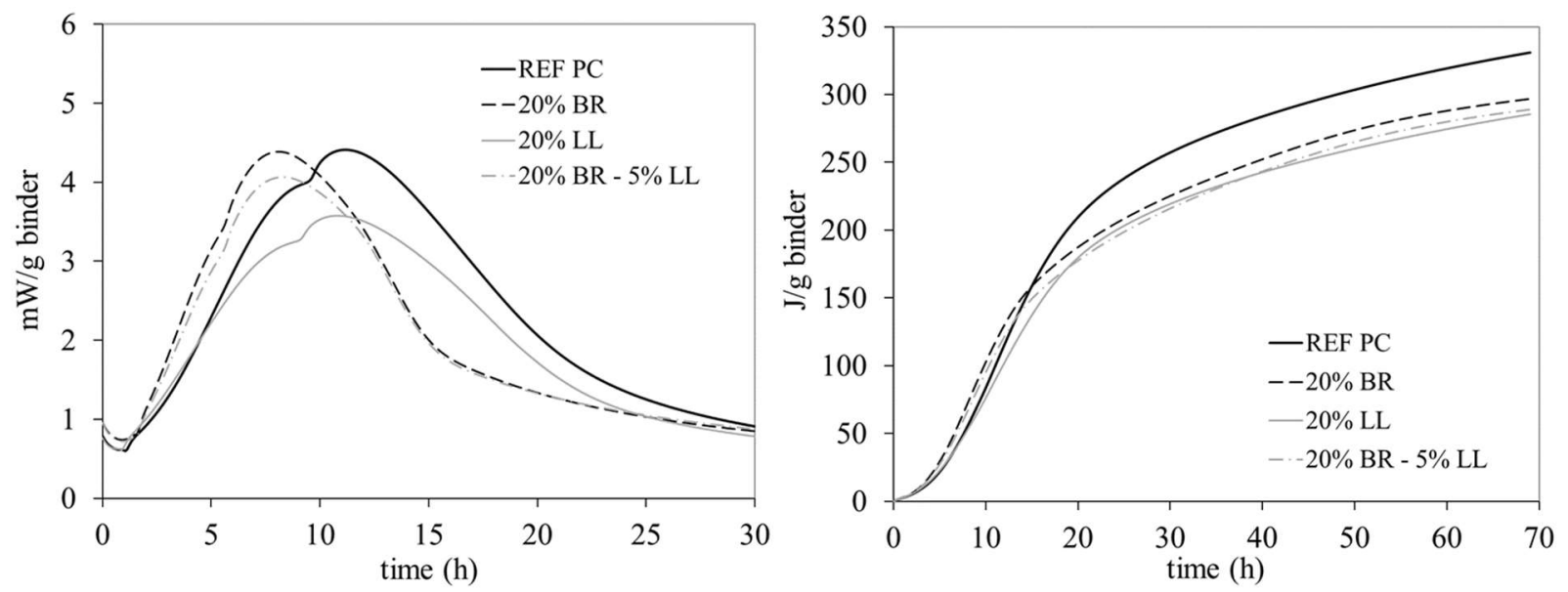

Figure 4- Thermal power (left) and cumulative heat (right) of REF PC (100\% CEMI) and pastes with $20 \% \mathrm{BR}, 20 \% \mathrm{LL}$ and $20 \% \mathrm{BR}+5 \% \mathrm{LL}$ replacement of $P C$ (LL = limestone filler)

Additionally, mortars were prepared by replacing PC with $20 \%$ BR and 5\% limestone and the compressive strength was tested after 1, 7, 28 and 91 days. The results are given Table 5. After 1 day the strength of the mortar with $20 \%$ BR was $84 \%$ of the reference CEM I and considerably higher than the strength of the mortar with $25 \%$ limestone. However, after 7 days and onwards the strength of the mortar with $25 \%$ limestone and the mortar with $20 \%$ BR and $5 \%$ limestone were about the same, reaching about $70 \%$ of the strength of the reference CEM I. It is known that increased alkali content may increase early strength but decrease final strength [29]. BR contains $9 \% \mathrm{Na}_{2} \mathrm{O}$ which might increase the 1-day strength. But from 7 days onwards the strength was similar as compared when using only limestone as cement replacement.

Table 5 - Compressive strength of mortars with and without replacement of cement by limestone or bauxite residue

\begin{tabular}{ccccc}
\hline & 1 day & 7 days & 28 days & 91 days \\
\hline 100\% CEM I & $35.2( \pm 1.1)$ & $58.3( \pm 1.5)$ & $66.1( \pm 0.5)$ & $72.9( \pm 2.0)$ \\
$75 \%$ CEM I + 25\% LL & $20.2( \pm 0.2)$ & $39.9( \pm 1.0)$ & $45.9( \pm 0.4)$ & $50.9( \pm 0.9)$ \\
$75 \%$ CEM I +20\% BR + 5\% LL & $29.7( \pm 0.5)$ & $40.2( \pm 0.3)$ & $43.9( \pm 0.5)$ & $49.8( \pm 0.2)$ \\
\hline
\end{tabular}

The high $\mathrm{pH}$ created by dissolved $\mathrm{NaOH}$ will also decrease the solubility of $\mathrm{Ca}(\mathrm{OH})_{2}$ and slow down any late pozzolanic reaction. A pH of 14 reduces the solubility of $\mathrm{Ca}(\mathrm{OH})_{2}$ by $2000 \mathrm{x}$ compared to $\mathrm{pH} 12.5$ in equilibrium with pure calcium hydroxide. Furthermore, when most of the water is used up by cement hydration the dissolved alkali hydroxides from BR get concentrated in the pore solution. Sodium $(\mathrm{Na})$ strongly coordinates 6 water molecules and consequently the activity of water decreases which might stop or slow down the hydration process. This might 
explain why the BR shows very good reactivity in $\mathrm{BR} / \mathrm{CH}$ and $\mathrm{R}^{3}$ pastes where excess of water is used, but relatively poor performance in mortars at late ages. The alkali content of BR might not only have a negative effect on the strength development but will also cause problems with regard to detrimental alkali-aggregate reactions (AAR). Therefore, efforts need to be made to reduce the alkaline content of BR without compromising the reactivity too much.

\section{2}

\section{Efforts to reduce the amount of soluble sodium}

\subsubsection{Co-Calcination of bauxite residue with other constituents}

The application of untreated bauxite as cement replacement in steel reinforced concrete is limited by the high alkali-release to the pore water caused by its interaction with calcium hydroxide from cement hydration. This may promote alkali-aggregate reactions (AAR) leading to swelling and subsequent cracking of the concrete and therefore hinder generic use of bauxite residue as cement replacement despite its good pozzolanic reactivity. A former study [30] showed that co-calcining $80 \%$ bauxite residue and $20 \%$ kaolin resulted in the formation of nepheline and reduced the alkali release. Increasing residence time in the furnace from 18 to $60 \mathrm{~min}$ did not improve the results [30]. For the current study it was therefore decided to use $70 \%$ bauxite residue combined with $30 \%$ kaolin in case the kaolin content was the limiting factor. The calcined samples were compared to not calcined reference samples (see Table 3).

The X-ray diffraction profiles of the calcined blends of BR and kaolin are plotted in Figure 5. All kaolin is transformed to metakaolin or has reacted with $\mathrm{BR}$ already at $800^{\circ} \mathrm{C}$ as there are no peaks of kaolinite left. At $800^{\circ} \mathrm{C}$ the main peaks found are due to sodalite and hematite remains from the BR. At $1000^{\circ} \mathrm{C}$, the formation of new peaks appears, and the sample becomes more crystalline due to recrystallisation of high temperature phases. The main phase formed from reaction of BR and kaolinite was nepheline $\left((\mathrm{Na}, \mathrm{K}) \mathrm{AlSiO}_{4}\right)$ with low potassium content, as the main phase to bind $\mathrm{Na}$, confirming the findings of [30].

All blends were mixed with portlandite $(\mathrm{CH})$ or cement and leaching of alkalis was investigated. The concentrations of sodium $(\mathrm{Na})$ released after $24 \mathrm{~h}$ from all the samples mixed with $\mathrm{CH}$ are listed in Table 6, while sodium and potassium released from the cement pastes after $40 \mathrm{~d}$ of hydration are given in Table 7. The concentration of hydroxyl ions is based on the sum of $\mathrm{Na}$ and $\mathrm{K}$ molarity and the corresponding $\mathrm{pH}$ calculated.

When measuring the amount of released $\mathrm{Na}$ in pastes with lime, $\mathrm{Na}$ leaching was significantly reduced. The concentration of $\mathrm{Na}$ released from the 70/30 BR/Kaolin blend not calcined was 30 times higher than the amount of sodium released from the blend calcined at $1000^{\circ} \mathrm{C}(6900 \mathrm{vs} .230$ $\mathrm{mg} / \mathrm{l})$ ). However, in the tests made with cement pastes the amount of $\mathrm{Na}$ released is only reduced by a factor of $2.5(16000 / 6300)$, or by a factor of $3.1((16000-1600) /(6300-1600))$ when sodium contribution from cement $(1600 \mathrm{mg} / \mathrm{l})$ is accounted for.

Yujiang et al. [31] showed that nepheline is stable in saturated $\mathrm{Ca}(\mathrm{OH})_{2}$ solution, but decomposes when alkalis $\left(\mathrm{Na}_{2} \mathrm{O}\right.$ and $\left.\mathrm{K}_{2} \mathrm{O}\right)$ is added to the solution. This might also explain the comparably 
low Na release of the co-calcined materials mixed with $\mathrm{Ca}(\mathrm{OH})_{2}$ solution in this study. Other feldspar minerals were also reported to react in alkaline solutions and even show signs of pozzolanic reactivity [32].

Samples 4, 5 and 6 separated after mixing in cement pastes and had free water on the top after curing for 40 days due to the much lesser water demand. Hence the free water was decanted off and analysed separately before pore water extraction. The slightly lower concentrations in the surface water compared to the pore water of the samples was as expected since alkalis released to the pore water on a later stage must diffuse through the dense matrix in order to equilibrate with the surface water.

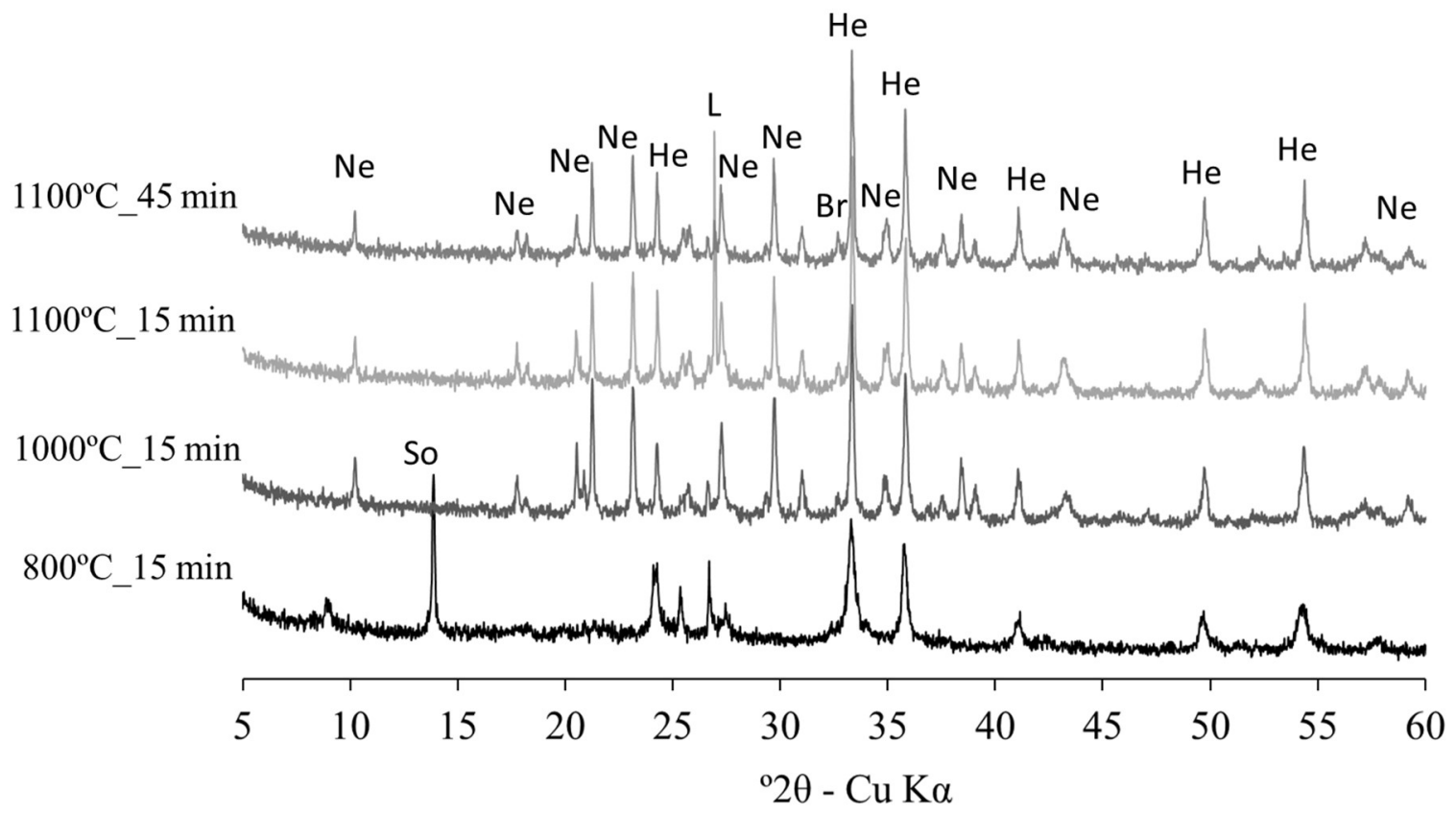

Figure 5 - XRD of calcined BR/kaolin blends (Ne = nepheline, $B r=$ bredigite, $L=$ Leucite, $S o=$ sodalite and $\mathrm{He}=$ hematite).

Table 6-Alkali release from the 24 h test with lime. All samples mixed with lime in a ratio of 1:1

\begin{tabular}{lll}
\hline No. & Sample & $\mathrm{Na}(\mathrm{mg} / \mathrm{L})$ \\
\hline 1 & $100 \% \mathrm{BR}$ & 7600 \\
2 & $70 / 30 \mathrm{BR} / \mathrm{K}-$ not calcined & 6900 \\
3 & $70 / 30 \mathrm{BR} / \mathrm{K}-800^{\circ} \mathrm{C} ; 15 \mathrm{~min}$ & 1060 \\
4 & $70 / 30 \mathrm{BR} / \mathrm{K}-1000^{\circ} \mathrm{C} ; 15 \mathrm{~min}$ & 230 \\
5 & $70 / 30 \mathrm{BR} / \mathrm{K}-1100^{\circ} \mathrm{C} ; 15 \mathrm{~min}$ & 180 \\
6 & $70 / 30 \mathrm{BR} / \mathrm{K}-1100^{\circ} \mathrm{C} ; 45 \mathrm{~min}$ & 170 \\
\hline
\end{tabular}


Nordic Concrete Research - Publ. No. NCR 62 - ISSUE 1 / 2020 - Article 1, pp. 1-20

Table 7 - Alkali release when samples are mixed with cement after 40 days curing

\begin{tabular}{llllll}
\hline No & Sample & $\begin{array}{l}\mathrm{Na} \\
(\mathrm{mg} / \mathrm{L})\end{array}$ & $\begin{array}{l}\mathrm{K} \\
(\mathrm{mg} / \mathrm{L})\end{array}$ & $\mathrm{OH}^{-}(\mathrm{mM})$ & $\mathrm{pH}$ \\
\hline 1 & $100 \% \mathrm{BR}$ & 21000 & 3600 & 1005 & 14.00 \\
2 & $70 / 30 \mathrm{BR} / \mathrm{K}-$ not calcined & 16000 & 3600 & 788 & 13.90 \\
3 & $70 / 30 \mathrm{BR} / \mathrm{K}-800^{\circ} \mathrm{C} ; 15 \mathrm{~min}$ & 14000 & 3400 & 696 & 13.84 \\
\hline 4 & $70 / 30 \mathrm{BR} / \mathrm{K}-1000^{\circ} \mathrm{C} ; 15 \mathrm{~min}$ & 6300 & 4500 & 389 & 13.59 \\
& Surface water of above & 5600 & 4500 & 359 & 13.56 \\
\hline 5 & $70 / 30 \mathrm{BR} / \mathrm{K}-1100^{\circ} \mathrm{C} ; 15 \mathrm{~min}$ & 4500 & 4100 & 301 & 13.48 \\
& Surface water of above & 3900 & 3800 & 268 & 13.43 \\
\hline 6 & $70 / 30 \mathrm{BR} / \mathrm{K}-1100^{\circ} \mathrm{C} ; 45 \mathrm{~min}$ & 5400 & 4400 & 347 & 13.54 \\
& Surface water of above & 3800 & 3900 & 265 & 13.42 \\
\hline
\end{tabular}

Due to the formation of nepheline and thus the increased $\mathrm{Na}$ binding (decreased amount of leachable $\mathrm{Na}$ ), the reactivity of the material decreased. The results from the $\mathrm{R}^{3}$-test comparing the reactivity of the new calcined blends with the original BR are given in Table 8 . The highest amount of bound water was obtained for the $70 / 30 \mathrm{BR} / \mathrm{K}$ blend calcined at $800^{\circ} \mathrm{C}$. At this temperature, kaolin was activated to metakaolin, a very effective pozzolan [33]. 70/30 BR/K blend calcined at $1000^{\circ} \mathrm{C}$ gave about the same amount of bound water as a fly ash [2] regularly used by Norcem in their blended cements. The second highest amount of chemical bound water was measured for the pure BR sample due to the formation of larger amounts of monocarboaluminate hydrate type AFm phase (Figure 6). The reactivity decreased with increasing calcination temperature. However, the reactivity is still comparable to that of fly ash and higher than that of limestone filler. Actually, using limestone filler as SCM in the $\mathrm{R}^{3}$-test should not lead to any bound water unless gypsum is formed in the reaction between calcium hydroxide and potassium sulphate or water molecules strongly bond on the high surface of calcium hydroxide by hydrogen bonds. In fact, the used limestone filler consists only of about $76 \% \mathrm{CC}$. The residual $24 \%$ are comprised of about $9 \%$ feldspars, $5 \%$ quartz, $4 \%$ pyroxenes and $6 \%$ micas and other minerals.

In previous tests (Table 5) the 28-day compressive strength was reduced considerably when $20 \%$ of PC was replaced with BR. In new mortar tests only $12 \%$ of PC was replaced with new blends of $\mathrm{BR}$ and $\mathrm{K}$ calcined at different temperatures. The average compressive strength with their standard deviations of the mortars after 2 days ( 2 parallels) and 28 days (4 parallels) curing are presented in Table 9. The strength of the mortar where cement is replaced by non-calcined 70/30 $\mathrm{BR} / \mathrm{Kaolin}$ is just slightly below the two references as expected from the chemical bound water in Table 8. However, the lower value for the blend calcined at $800^{\circ} \mathrm{C}$ was not expected considering the chemical bound water in Table 8 and the fact that kaolin was converted to metakaolin. Metakaolin is water demanding, and it is possible that this was a stiffer mix than those calcined at higher temperatures and thereby entrained and kept some air. The mass of the prisms could reveal if there was excessive air entrainment or compaction flaws, but this was not reported. The mortars where the cement was replaced with $70 / 30 \mathrm{BR} / \mathrm{Kaolin}$ blend calcined at $1000^{\circ} \mathrm{C}$ and above had all about the same strength considering the standard deviations, and about $91 \%$ of the reference with $100 \%$ cement. 
Table 8 - Chemical bound water measured with the $R^{3}$-test after 2 days curing at $40^{\circ} \mathrm{C}$

\begin{tabular}{ll}
\hline Sample & $\begin{array}{l}\text { Bound water } \\
\left.\text { (\% by dry weight at } 350^{\circ} \mathrm{C}\right)\end{array}$ \\
\hline $100 \% \mathrm{BR}$ & 10.5 \\
$70 / 30 \mathrm{BR} / \mathrm{K}-$ not calcined & 7.2 \\
$70 / 30 \mathrm{BR} / \mathrm{K}-800^{\circ} \mathrm{C} ; 15 \mathrm{~min}$ & 12.6 \\
$70 / 30 \mathrm{BR} / \mathrm{K}-1000^{\circ} \mathrm{C} ; 15 \mathrm{~min}$ & 3.2 \\
$70 / 30 \mathrm{BR} / \mathrm{K}-1100^{\circ} \mathrm{C} ; 15 \mathrm{~min}$ & 2.6 \\
$70 / 30 \mathrm{BR} / \mathrm{K}-1100^{\circ} \mathrm{C} ; 45 \mathrm{~min}$ & 2.5 \\
Fly Ash & 3.4 \\
Limestone filler & 1.1 \\
\hline
\end{tabular}

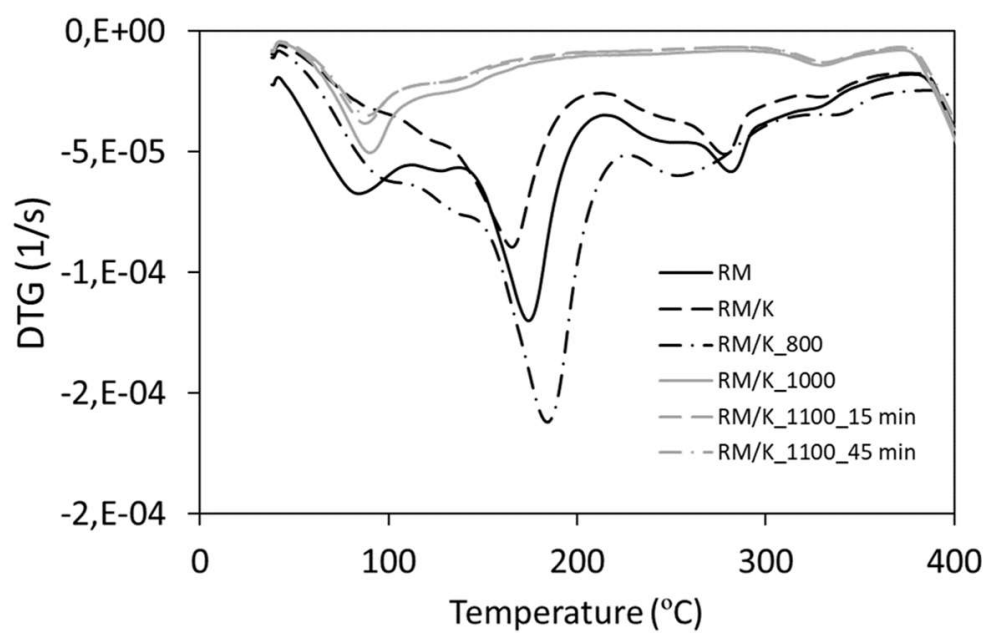

Figure 6-DTG curve of $R^{3}$ test samples from co-calcination experiments described in Table 3

Table 9 - Compressive strength of mortars where 12\% cement is replaced by the samples indicated

\begin{tabular}{lll}
\hline Sample & 2 days $(\mathrm{MPa})$ & 28 days $(\mathrm{MPa})$ \\
\hline $100 \% \mathrm{CEM} \mathrm{I}$ & $35.3( \pm 0.0)$ & $54.1( \pm 0.6)$ \\
$88 \% \mathrm{CEM} \mathrm{I}+12 \% \mathrm{LL}$ & $35.9( \pm 0.4)$ & $53.4( \pm 0.8)$ \\
$88 \% \mathrm{CEM} \mathrm{I}+12 \% 70 / 30 \mathrm{BR} / \mathrm{K}-$ not calcined & $34.3( \pm 0.3)$ & $51.2( \pm 1.5)$ \\
$88 \% \mathrm{CEM} \mathrm{I}+12 \% 70 / 30 \mathrm{BR} / \mathrm{K}-800^{\circ} \mathrm{C} ; 15 \mathrm{~min}$ & $29.2( \pm 0.1)$ & $42.2( \pm 0.7)$ \\
$88 \% \mathrm{CEM} \mathrm{I}+12 \% 70 / 30 \mathrm{BR} / \mathrm{K}-1000^{\circ} \mathrm{C} ; 15 \mathrm{~min}$ & $30.2( \pm 1.1)$ & $49.0( \pm 0.7)$ \\
$88 \% \mathrm{CEM} \mathrm{I}+12 \% 70 / 30 \mathrm{BR} / \mathrm{K}-1100^{\circ} \mathrm{C} ; 15 \mathrm{~min}$ & $30.4( \pm 0.8)$ & $49.1( \pm 0.7)$ \\
$88 \% \mathrm{CEM} \mathrm{I}+12 \% 70 / 30 \mathrm{BR} / \mathrm{K}-1100^{\circ} \mathrm{C} ; 45 \mathrm{~min}$ & $31.2( \pm 0.4)$ & $49.4( \pm 0.8)$ \\
\hline
\end{tabular}

\subsubsection{Cooking of bauxite residue}

Blends of (a) $60 \% \mathrm{BR}$ and $40 \% \mathrm{CH}$ and (b) $60 \% \mathrm{BR}, 20 \% \mathrm{CH}$ and $20 \% \mathrm{CS}_{2} \mathrm{H}_{2}$ were prepared and cooked with excess water $(\mathrm{w} / \mathrm{b}=5.7)$ on a laboratory heating plate while stirring constantly. A recent study showed that considerable amounts of $\mathrm{Na}_{2} \mathrm{O}$ can be recovered from $\mathrm{BR}$ by reaction with $\mathrm{CaO}$ in a hydrothermal process [34]. Before and after cooking, the $\mathrm{BR}$ and the reacted samples $\left(\mathrm{BR} / \mathrm{CH}\right.$ and $\left.\mathrm{BR} / \mathrm{CH} / \mathrm{CS}_{\mathrm{S}} \mathrm{H}_{2}\right)$ were washed with water. The water after each step of washing and cooking was filtrated and analysed with respect to sodium (Na) content and the results are shown in Table 10. The results show that some amounts of sodium are easily soluble and can simply be removed by washing the BR with water. However, more sodium is released 
during the cooking process as seen from the water analysis of samples "BR/CH after cooking" and "BR/CH/CŜH 2 after cooking".

Table 10 - Water analysis after washing and cooking of BR and BR blends

\begin{tabular}{lll}
\hline Water sample & $\mathrm{pH}$ & $\mathrm{Na}(\mathrm{mg} / \mathrm{L})$ \\
\hline $\mathrm{BR}$ washing cycle 1 & 13.0 & 1800 \\
$\mathrm{BR}$ washing cycle 2 & 12.5 & 540 \\
$\mathrm{BR} / \mathrm{CH}$ after cooking & 13.3 & 4600 \\
$\mathrm{BR} / \mathrm{CH}$ washed (after cooking) & 13.1 & 840 \\
$\mathrm{BR} / \mathrm{CH} / \mathrm{C} \hat{\mathrm{S}} \mathrm{H}_{2}$ after cooking & 12.9 & 5000 \\
$\mathrm{BR} / \mathrm{CH} / \mathrm{CS} \mathrm{H}_{2}$ washed after cooking) & 12.44 & 590 \\
\hline
\end{tabular}

Following a complete mass balance taking into account concentrations and amounts of water/slurry in each step, washing of BR and cooking with calcium hydroxide theoretically removed $38.8 \%$ of the original $\mathrm{Na}_{2} \mathrm{O}$ content, while cooking with calcium hydroxide and gypsum removed $48.8 \%$ in comparison. However, XRF results of the dried materials showed an even higher reduction in $\mathrm{Na}_{2} \mathrm{O}$ in the dried products. The dried $\mathrm{BR} / \mathrm{CH}$ powder had a measured $\mathrm{Na}_{2} \mathrm{O}$ content of $2.4 \%$ while the dried $\mathrm{BR} / \mathrm{CH} / \mathrm{CS} \mathrm{H}_{2}$ powder had a $\mathrm{Na}_{2} \mathrm{O}$ content of $3.8 \%$. This results in a $73.9 \%$ and $58.7 \%$ reduction of the initial $\mathrm{Na}_{2} \mathrm{O}$ content. The reason for including gypsum was to initially convert all adsorbed sodium hydroxide to sodium sulphate and precipitating calcium hydroxide $\left(2 \mathrm{NaOH}+\mathrm{CaSO}_{4}=\mathrm{Na}_{2} \mathrm{SO}_{4}+\mathrm{Ca}(\mathrm{OH})_{2}\right)$; as otherwise $\mathrm{NaOH}$ would supress the solubility of calcium hydroxide and slow down the reaction. During the cooking process the BR will react with $\mathrm{CH}$ and gypsum $\left(\mathrm{CS}^{\mathrm{S}} \mathrm{H}_{2}\right)$ if present.

The DTG curve of the reacted blends after cooking are shown in Figure 7. In the BR/CH sample peaks are visible at around 150,330 and $500^{\circ} \mathrm{C}$. The peak at around $500^{\circ} \mathrm{C}$ derives from unreacted $\mathrm{CH}$. Calculations based on the weight loss in the temperature region of $\mathrm{CH}$ decomposition showed that about $14 \% \mathrm{CH}$ (by dry weight at $550^{\circ} \mathrm{C}$ ) are left in the reacted product. Initially, the dry blend contained $40 \% \mathrm{CH}$. This confirms a pozzolanic reaction of the $\mathrm{BR}$ with $\mathrm{CH}$. The peak at $330^{\circ} \mathrm{C}$ might be due to some residual goethite and gibbsite from the BR potentially overlapping with katoite. The formation of katoite was shown earlier in the reaction of $\mathrm{BR}$ with $\mathrm{CH}$ and also confirmed in this blend with XRD analysis (Figure 8). The peak around $160^{\circ} \mathrm{C}$ is typically for the formation of AFm phases in the pozzolanic reaction.

Interestingly, when $\mathrm{BR}$ was cooked with $\mathrm{CH}$ and $\mathrm{CS} \mathrm{S}_{2}$, all $\mathrm{CH}$ seemed to be consumed in the reaction. However, only half the amount of calcium hydroxide relative to BR was added. Additional peaks appeared at around 120,170 and $280^{\circ} \mathrm{C}$, plus some minor peaks between 300 and $400^{\circ} \mathrm{C}$. These small signals might potentially derive from some disturbance of the instrument stability during the measurement. The peak at $120^{\circ} \mathrm{C}$ can potentially be due to the formation of ettringite from reaction of gypsum with the aluminate species in $\mathrm{BR}$, while the peak at $280^{\circ} \mathrm{C}$ might be associated with sodalite. Both blends were cooked and dried open (not sealed) which might have promoted a partly carbonation of the samples. Peaks for carbonate phases (probably calcite) are detected between 700 and $800{ }^{\circ} \mathrm{C}$. The XRD results of the BR blend cooked with $\mathrm{CH}$ and the blend cooked with $\mathrm{CH}$ and $\mathrm{CS}_{2} \mathrm{H}_{2}$ are shown in Figure 8. The XRD confirms that a 
significant amount of AFm phase in the form of a type of calcium hemicarboaluminate hydrate (Hc) was formed in the blend with $\mathrm{CH}$ and $\mathrm{CS}_{2} \mathrm{H}_{2}$. In the blend with $\mathrm{CH}$ only, more monocarboaluminate hydrate (Mc) was detected. The peaks for $\mathrm{Hc}$ and $\mathrm{Mc}$ are not exactly at the ideal positions for the pure mineral phases. This is due to a differing degree of Fe substitution for $\mathrm{Al}$ in the structure of the phases. Small amounts of ettringite (AFt) were found in the blend with $\mathrm{CH}$ and $\mathrm{CSSH}_{2}$. When cooked with only $\mathrm{CH}$, formation of katoite was observed as mentioned above. The XRD also confirms that gypsum and $\mathrm{CH}$ are consumed when cooking with $\mathrm{CH}$ and $\mathrm{CS} \mathrm{H}_{2}$, as no peaks were detected.

The reactivity of the cooked samples measured with the $\mathrm{R}^{3}$ test was decreased compared to the untreated BR sample but higher compared to the co-calcined samples calcined at $1000^{\circ} \mathrm{C}$ (Table 11). Heating the cooked samples at $400^{\circ} \mathrm{C}$ to dehydroxylate the formed hydration products increased the reactivity further. However, the reactivity appeared quite good in terms of bound water for the cooked $\mathrm{BR} / \mathrm{CH} / \mathrm{CSS}_{2}$ sample and not much was gained by drying at $400^{\circ} \mathrm{C}$.

Drying at $400^{\circ} \mathrm{C}$ potentially only decomposes the hydrate phases and rehydrating by the addition of water might be the reason for the extra bound water. In such a case, the rheology for cement pastes containing the processed BR sample might be negatively affected due to a fast reaction upon mixing. To investigate the hydration of cement pastes containing the cooked BR samples, isothermal calorimetry experiments were performed. Figure 9 shows the results of isothermal calorimetry of pastes containing $20 \%$ of the cooked BR samples from Table 11.

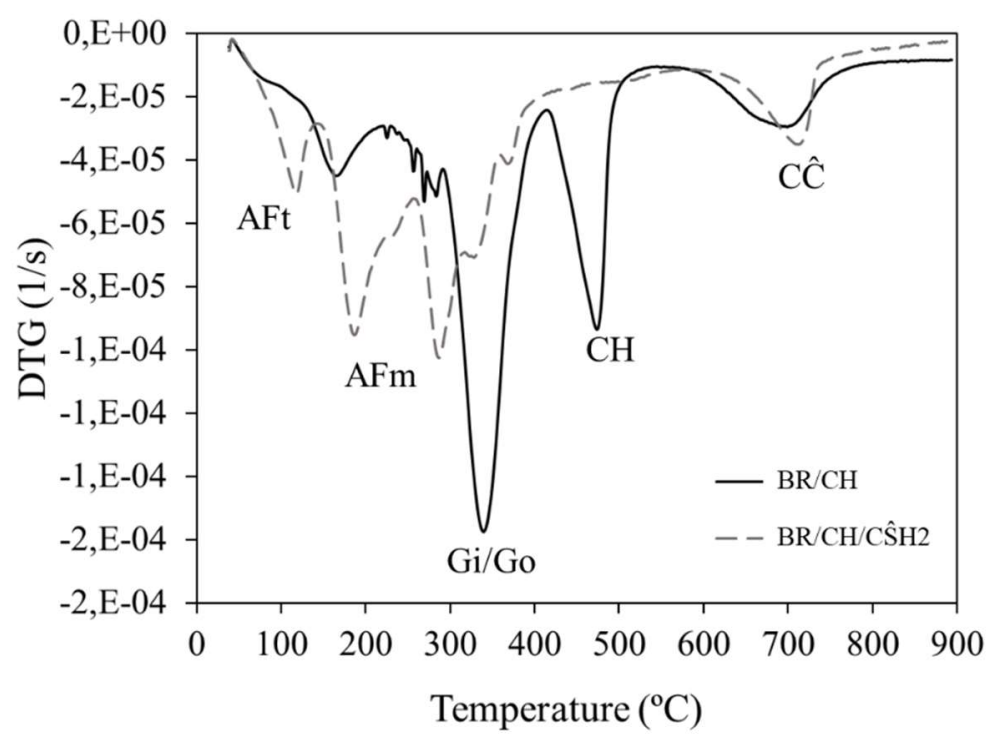

Figure 7 - DTG of the BR blends cooked with only $\mathrm{CH}(\mathrm{BR} / \mathrm{CH})$ and with $\mathrm{CH}$ and gypsum (BR/CH/CSH2), $\mathrm{CH}=$ portlandite, $\mathrm{Gi}=$ gibbsite, $\mathrm{Go}=$ goethite, $\mathrm{C} \hat{\mathrm{C}}=$ calcite 


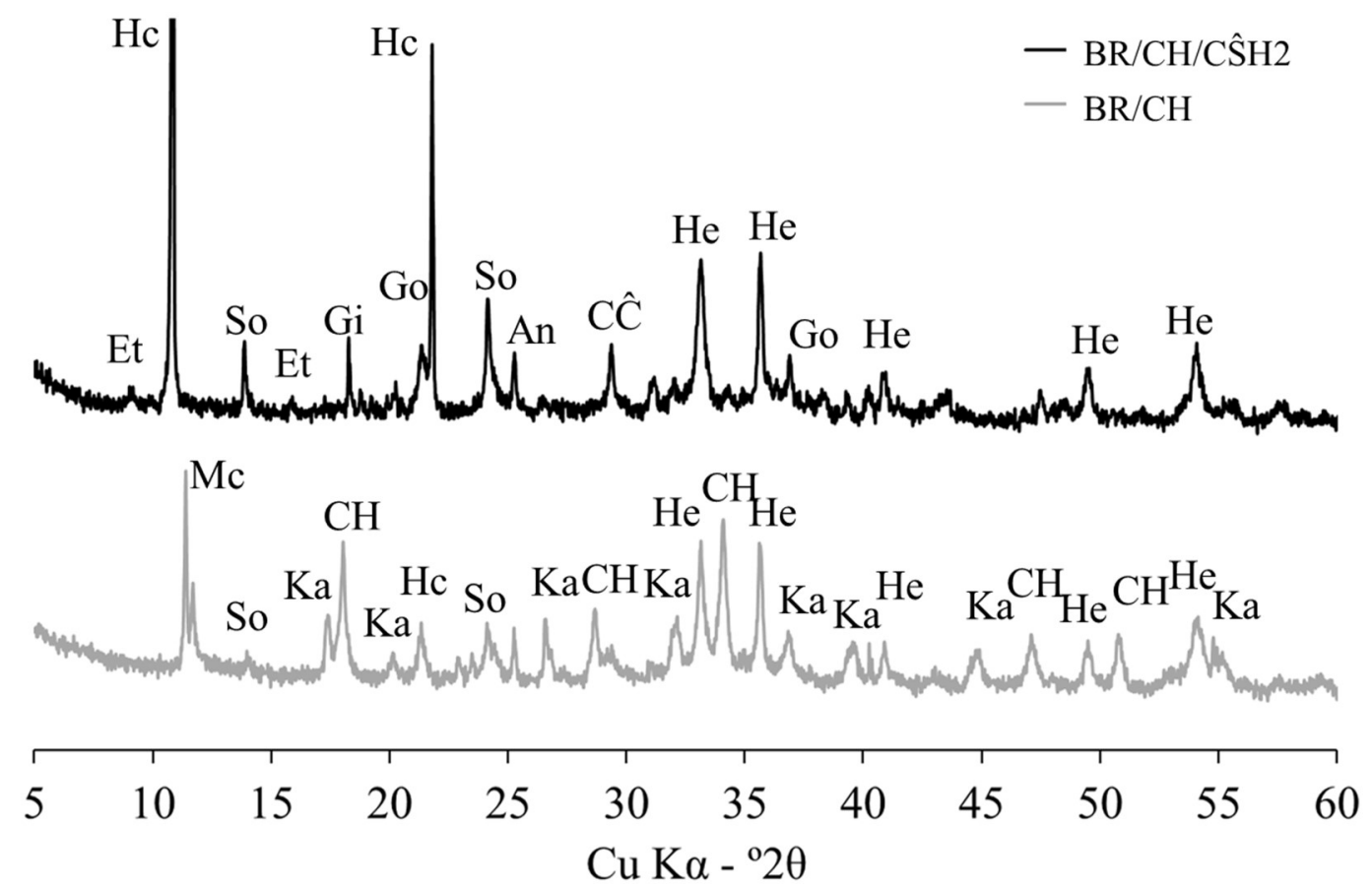

Figure $8-X R D$ of $\mathrm{BR} / \mathrm{CH} / \mathrm{CS} \mathrm{H}_{2}$ and $\mathrm{BR} / \mathrm{CH}$ blend after cooking (Hc = calcium hemicarboaluminate hydrate, $M c=$ calcium monocarboaluminate hydrate; $E t=$ ettringite, $K a=$ Katoite; $\mathrm{CH}=$ calcium hydroxide, $\mathrm{Gi}=$ gibbsite, $\mathrm{So}=$ sodalite, $\mathrm{He}=$ hematite and $\mathrm{Go}=$ goethite, An = anatase; $C \hat{C}=$ calcite)

Table 11 - Chemical bound water of cooked materials, measured with the $R^{3}$-test after 2 days curing at $40^{\circ} \mathrm{C}$

\begin{tabular}{ll}
\hline Sample & $\begin{array}{l}\text { Bound water } \\
\left(\% \text { by dry weight at } 350^{\circ} \mathrm{C}\right)\end{array}$ \\
\hline $\mathrm{BR} / \mathrm{CH}$ cooked and dried & 4.4 \\
$\mathrm{BR} / \mathrm{CH}$ cooked and heated to $400^{\circ} \mathrm{C}$ & 6.3 \\
\hline $\mathrm{BR} / \mathrm{CH} / \mathrm{CS} \mathrm{H}_{2}$ cooked and dried & 7.6 \\
$\mathrm{BR} / \mathrm{CH} / \mathrm{CS} \mathrm{H}_{2}$ cooked and heated to $400^{\circ} \mathrm{C}$ & 8.3 \\
\hline
\end{tabular}

All pastes containing cooked BR increased the water demand (higher viscosity of pastes) similarly as visually observed upon mixing with water. The initial heat development, right after inserting the samples into the calorimeter (not shown in Figure 9) was significantly increased with the samples heated at $400^{\circ} \mathrm{C}$. When cooked BR was blended with $\mathrm{PC}$, the hydration of all pastes was accelerated, BR/CH/CŜH2 - 400C showing the highest acceleration. PC blended with $\mathrm{BR} / \mathrm{CH} / \mathrm{CS} \mathrm{H} 2-400 \mathrm{C}$ shows additionally a higher reaction rate in the acceleration period as can be seen in the increased silicate and aluminate reaction peaks. A similar behaviour was observed for under-sulphated systems, SCMs with high surface area (e.g. calcined clays [35]) modifying the reactivity of the aluminate phases, and the so-called filler effect $[36,37]$. The cooked, but not extra heated samples, $(\mathrm{BR} / \mathrm{CH}$ and $\mathrm{BR} / \mathrm{CH} / \mathrm{CS} H 2)$ appear to have less influence on the hydration kinetics with a less pronounced acceleration and a slightly lower reaction rate in the acceleration period of the hydration. With regard to calorimetry and the reactivity of the different samples, an extra heating step at $400^{\circ} \mathrm{C}$ seems unnecessary. It remains to see if this extra chemical bound water will influence the actual strength in any way. This is an issue for further research. 

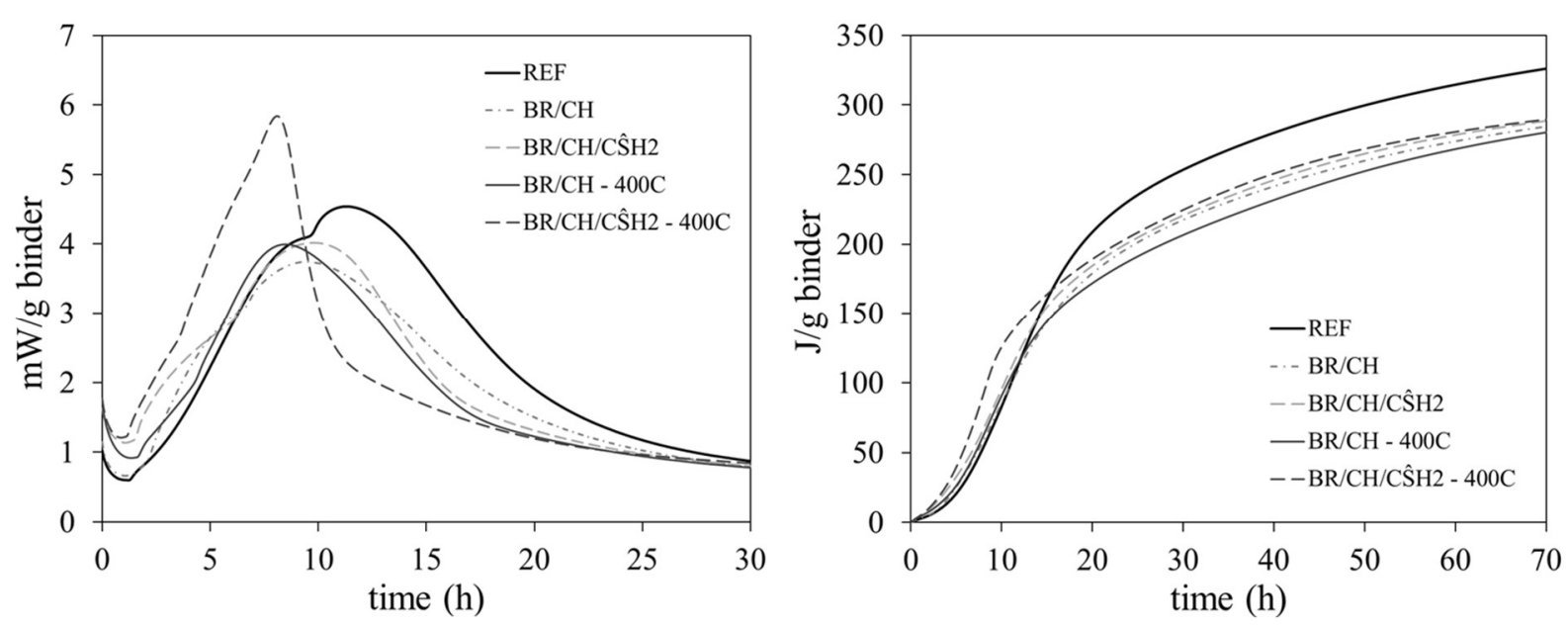

Figure 9 - Thermal power (left) and cumulative heat (right) of REF (100\% CEM I) and pastes with $20 \%$ BR cooked with $\mathrm{CH}$ or $\mathrm{CH}$ and $\mathrm{CS} H 2$ heated and not heated at $400^{\circ} \mathrm{C}$

5.

\section{CONCLUSIONS}

Bauxite residue (BR) as supplementary cementitious material

- Calcium hydroxide $(\mathrm{CH})$ consumption experiments showed that BR is a highly reactive pozzolana.

- The main hydration products in reaction with $\mathrm{CH}$ were katoite and carboaluminate hydrate AFm. In the presence of $C \hat{C}$ the main hydration products formed were monocarboaluminate hydrate on the expense of katoite.

- BR accelerated the early hydration of PC. However, the long-term strength evolution of mortars was reduced with addition of BR compared to reference with $100 \%$ cement.

- The high alkali content in BR probably has a negative impact on strength development while increasing the risk of AAR in concrete.

Attempts to reduce alkali leaching of $B R$

- Co-calcination of BR with kaolin $(\mathrm{K})$ resulted in increased binding of $\mathrm{Na}$ by the formation of nepheline and consequently reduced $\mathrm{Na}$ leaching. At the same time reactivity of the $\mathrm{BR} / \mathrm{K}$ blends decreased with increasing calcination temperature. Still, 12\% replacement of PC in mortars resulted in satisfying 28-day compressive strength.

- Washing and cooking of BR with calcium hydroxide or calcium hydroxide and gypsum resulted in an almost 75 and $60 \%$ reduction of initial $\mathrm{Na}_{2} \mathrm{O}$ content, respectively. During the cooking process $\mathrm{BR}$ reacted with the $\mathrm{CH}$ and $\mathrm{CS}_{\mathrm{S}} \mathrm{H}_{2}$ in hydration reactions, decreasing the reactivity. Still, results from the $\mathrm{R}^{3}$ test showed higher reactivity than compared with fly ash. Another heating to $400^{\circ} \mathrm{C}$ of the reacted blends increased the reactivity. Further research will reveal how this affects strength. 
BR can be an effective pozzolan and large source of supplementary cementitious material for the cement industry. At the same time, aluminium plants would reduce their environmental impact by avoiding landfills of alkaline BR waste. However, to be successfully used by the building industry potential AAR has to be mitigated by reducing the alkali content of BR with an economical feasible procedure. Further attempts will be made to optimize the cooking experiments conducted for this study and testing the performance of the processed BR in mortar and concrete. Further possibilities for alkali reduction will be investigated in the future (e.g. trying to produce a BR slag of high reactivity and reduced $\mathrm{Na}$ leaching).

\section{7.}

\section{ACKNOWLEDGEMENT}

The results presented in this paper are part of the research project DARE2C; Durable Aluminium Reinforced Environmentally-friendly Concrete Construction, supported by grant no. 269767 from the Research Council of Norway. Industrial partners are Hydro, Norcem, Veidekke and Overhalla Betong.

8.

\section{REFERENCES}

1. Hind A R, Bhargava S K \& Grocott S C: "The surface chemistry of Bayer process solids: a review". Colloids and Surfaces; A: Physiochemical and Engineering Aspects, No. 146, 1998, pp. 359-374.

2. Yang J \& Xiao B: "Development of unsintered construction materials from red mud wastes produced in the sintering alumina process". Construction and Building Materials, Vol. 22, No. 12, 2008, pp. 2299-2307.

3. Rai S, Wasewar K, Mukhopadhyay J, Yoo C \& Uslu H: "Neutralization and Utilization of red mud for its better waste management". Arch. Environ. Sci., Vol. 6, 2012.

4. Liu X \& Zhang N: "Utilization of red mud in cement production: a review". Waste Management \& Research, Vol. 29, No. 10, 2011, pp. 1053-1063.

5. Khairul M A, Zanganeh J \& Moghtaderi B: "The composition, recycling and utilisation of Bayer red mud". Resources, Conservation and Recycling, Vol. 141, 2019, pp. 483-498.

6. Lima M S S, Thives L P, Haritonovs V \& Bajars K: "Red mud application in construction industry: review of benefits and possibilities". IOP Conference Series: Materials Science and Engineering, Vol. 251, 2017, pp. 12-33.

7. Scrivener K L, John V M \& Gartner E M: "Eco-efficient cements: Potential economically viable solutions for a low-CO2 cement-based materials industry". Cement and Concrete Research, Vol. 114, 2018, pp. 2-26.

8. Boden $\mathrm{T} \&$ Andres B: "Global $\mathrm{CO} 2$ emissions from fossil-fuel burning, cement manufacture, and gas flaring". Tennesse Carbon Dioxide Information Analysis Centre, Oak Ridge National Laboratory, 2016,

9. Venkatesh C, Chand M S R \& Nerella R: "A State of the Art on Red Mud as a Substitutional Cementitious Material". Annales de Chimie: Science des Materiaux, Vol. 43, No. 2, 2019, pp. 99-106. 
10. Ribeiro D V, Labrincha J A \& Morelli M R: "Effect of red mud addition on the corrosion parameters of reinforced concrete evaluated by electrochemical methods". Revista IBRACON de Estruturas e Materiais, Vol. 5, 2012, pp. 451-467.

11. Deshmukh M P, Sarode D D \& Claude A: "Effect of partial replacement of crushed fine aggregates with an industrial waste (red mud) on chloride penetration of concrete.". International Journal of Current Engineering and Technology, Vol. 6, No. 4, 2014, pp. 4026-4029.

12. Rajendran R R, Pillaib E B \& Santhakumai A R: "Effective utilization of redmud bauxite waste as a replacement of cement in concrete for environmental conservation". Ecology, Environment and Conservation, Vol. 19, 2013, pp. 247-255.

13. Kótai L, Sajó I, Gács I, Papp K, Bartha A \& Bánvölgyi G: "An Environmentally Friendly Method for Removing Sodium in Red Mud". Chemistry Letters - CHEM LETT, Vol. 35, 2006, pp. 1278-1279.

14. Xue S-g, Wu Y-j, Li Y-w, Kong X-f, Zhu F, William H, Li X-f \& Ye Y-z: "Industrial wastes applications for alkalinity regulation in bauxite residue: A comprehensive review". Journal of Central South University, Vol. 26, No. 2, 2019, pp. 268-288.

15. Jansen D, Goetz-Neunhoeffer F, Stabler C \& Neubauer J: "A remastered external standard method applied to the quantification of early OPC hydration". Cement and Concrete Research, Vol. 41, No. 6, 2011, pp. 602-608.

16. Madsen Ian C, Scarlett Nicola V Y \& Kern A: "Description and survey of methodologies for the determination of amorphous content via X-ray powder diffraction". Zeitschrift für Kristallographie Crystalline Materials, Vol. 226, No. 12, 2011, pp. 944.

17. O'Connor B H \& Raven M D: "Application of the Rietveld Refinement Procedure in Assaying Powdered Mixtures". Powder Diffraction, Vol. 3, No. 1, 1988, pp. 2-6.

18. Avet F, Snellings R, Alujas Diaz A, Ben Haha M \& Scrivener K: "Development of a new rapid, relevant and reliable (R3) test method to evaluate the pozzolanic reactivity of calcined kaolinitic clays". Cement and Concrete Research, Vol. 85, 2016, pp. 1-11.

19. Dilnesa B Z: "Fe-containing hydrates and their fate during cement hydration: thermodynamic data and experimental study". ( $\mathrm{PhD}$ Thesis), École Polytechnique Fédérale de Lausanne, 2011,

20. Justnes H, Engelsen C, Danner T \& Strøm M. "Evaluation of Ceramic Waste from Goa as SCM". Proceedings, 3rd International Conference on Calcined Clays for Sustainable Concrete, Delhi, India, 2019.

21. De Weerdt K \& Justnes H. "Microstructure of Binder from the Pozzolanic Reaction between Lime and Siliceous Fly Ash, and the Effect of Limestone Addition". Proceedings, 1st Int. Conf. on Microstructure Related Durability of Cementitious Composites, 13-15 October, 2008 , Nanjing, China, pp. 107-116, RILEM Proceeding PRO 61., 2008.

22. De Weerdt K, Justnes H, Kjellsen K O \& Sellevold E. "Synergic Reactions in Triple Blended Cements". Proceedings, 11th NCB International Seminar on Cement and Building Materials, New Delhi, India, 2009, pp. 257-261.

23. De Weerdt K, Justnes H, Kjellsen K O \& Sellevold E: "Fly Ash Limestone Ternary Composite Cements: Synergy Effect at 28 days". Nordic Concrete Research, Vol. 42, 2010, pp. 51-70.

24. Danner T: "Reactivity of calcined clays". 2013:218 (PhD Thesis), Norwegian University of Science and Technology - NTNU, 2013, pp. 229

25. Danner T, Norden G \& Justnes H: "Characterisation of calcined raw clays suitable as supplementary cementitious materials". Applied Clay Science, Vol. 162, 2018, pp. 391402. 
26. Karen S, François A, Hamed M, Franco Z, Julien S, Wilasinee H \& Aurélie F: "Impacting factors and properties of limestone calcined clay cements (LC3)". Green Materials, Vol. 7, No. 1, 2019, pp. 3-14.

27. Jansen D, Goetz-Neunhoeffer F, Lothenbach B \& Neubauer J: "The early hydration of Ordinary Portland Cement (OPC): An approach comparing measured heat flow with calculated heat flow from QXRD". Cement and Concrete Research, Vol. 42, No. 1, 2012, pp. 134-138.

28. Ribeiro D V, Labrincha J A \& Morelli M R: "Potential use of natural red mud as pozzolan for Portland cement". Materials Research, Vol. 14, 2011, pp. 60-66.

29. Jawed I \& Skalny J: "Alkalies in cement: A review: II. Effects of alkalies on hydration and performance of Portland cement". Cement and Concrete Research, Vol. 8, No. 1, 1978, pp. 37-51.

30. De Noni A, Minatto F D, Pelisser F, Peterson M \& Montedo O R K. "Development of Supplementary Cementing Materials from Red Mud". Proceedings, 32nd International Conference and Exhibition of ICSOBA (The International Committee for Study of Bauxite, Alumina \& Aluminium), Zhengzhou, Henan Province, China, 2014, pp. 7.

31. Yujiang W, Min D \& Mingshu T: "Alkali release from aggregate and the effect on AAR expansion". Materials and Structures, Vol. 41, No. 1, 2007, pp. 159.

32. Van Aardt J \& Visser S: "Reaction of $\mathrm{Ca}(\mathrm{OH}) 2$ and of $\mathrm{Ca}(\mathrm{OH}) 2+\mathrm{CaSO} 4.2 \mathrm{H} 2 \mathrm{O}$ at various temperatures with feldspars in aggregates used for concrete making". Cement and Concrete Research, Vol. 8, No. 6, 1978, pp. 677-681.

33. Sabir B B, Wild S \& Bai J: "Metakaolin and calcined clays as pozzolans for concrete: a review". Cement and Concrete Composites, Vol. 23, No. 6, 2001, pp. 441-454.

34. Zhou B, Cao S, Chen F, Zhang F \& Zhang Y: "Recovery of Alkali from Bayer Red Mud Using $\mathrm{CaO}$ and/or MgO". Minerals, Vol. 9, No. 5, 2019, pp. 269.

35. Danner T, Norden G \& Justnes H: "Calcareous smectite clay as a pozzolanic alternative to kaolin". European Journal of Environmental and Civil Engineering, 2019, pp. 1-18.

36. Antoni M, Rossen J, Martirena F \& Scrivener K: "Cement substitution by a combination of metakaolin and limestone". Cement and Concrete Research, Vol. 42, No. 12, 2012, pp. 1579-1589.

37. Lothenbach B, Scrivener K \& Hooton R D: "Supplementary cementitious materials". Cement and Concrete Research, Vol. 41, No. 12, 2011, pp. 1244-1256. 